\title{
Inquiries and challenges bring joy and confidence
}

I hear that planting young grapevines in dry ground is necessary for making good wines. The planted grapevines try to spread their roots to take water and nutrients from the soil; consequently, they absorb plenty of mineral nutrients and good wines are produced. In many respects, the same is true of the development of young people who will become leaders of the next generation. However, I feel uneasy about the scholarship system and the provision of travel expenses and research funds for students that universities and colleges in Japan have recently emphasized as measures to reduce the doctoral vacancy rate. I fear that the students may receive excessive assistance from universities and colleges without fully understanding its significance. In this editorial, I would like to discuss the development of young people who will achieve responsible positions in the next generation.

The purpose of science is to improve our standard of living to make a contribution to society and to show youths the importance of interest in the marvels of nature and the great significance in the process of investigating them. Similarly, the role of universities, research institutions, and scientific societies is to improve present academic standards and to nurture the next generation of researchers. Particularly for the latter, it is important to make an impression on young people and let them experience the wonder and excitement of research activities. For baby boomers, who have increasingly shaped our society since World War II, there were ten or more classes in the same grade in their elementary school days, and they improved themselves through friendly rivalry from their childhood to support our society. We are now facing the retirement of a large number of baby boomers, and as a result, the responsibilities of the younger working generation will be more important than ever.

National universities were incorporated in April 2004, and in exchange for their independence they face severe management problems from a budgetary perspective. For this reason, academic-industrial cooperation is now strongly recommended, and high priorities are being given to the acquisition of large-scale competitive research funds and patent applications. If universities put emphasis only on fund-raising and safe research projects that can be completed in a short period of time, the spirit of taking on new challenges inherent in research will be lost. In addition, if an advisor assigns such research projects to students, they will undertake the projects only for the purpose of living up to his or her expectations. Therefore, if the aforementioned excessive assistance is provided not only for financial reasons but also for the advancement of research, no time allowance will be made for students and they will lose the chance to experience failures from which they could learn important lessons. What is important for the development of young, next-generation researchers is to teach them how to observe, think, and produce their own results; even small accomplishments through a trial-and-error process can boost confidence and let them know the importance of humility through these processes, rather than to instruct them to conduct an experiment to produce excellent research results. Thus, it is necessary to provide more opportunities for young people to experience many failures in terms of time and mental load and to educate them based on the concept that acquiring a wide range of knowledge is a key to solving problems, even if it is very inefficient. Acquisition of the skills required for education is important for university and college teachers.

Only scientists have the following privileges: making a new discovery after many years of hardships; experiencing absolute silence in an audience waiting for the announcement of groundbreaking findings during the presentation of a paper at a conference; success in the rigorous review of a hard-earned paper; citation of a published paper by unknown people from abroad; and the launch of a product using the methods developed, all of which are wonderful experiences for those who are directly engaged in research and development activities. I would like many young people to enjoy such wonderful experiences through research and development activities. If young people push themselves to the limit by believing in their abilities and continue their efforts with plenty of courage, they will find the value of impression made by themselves, and I want them to learn this from their own experiences. It is important for university researchers to cultivate the spirit of taking on new 
challenges that encourages themselves to believe in an invention or discovery, which may lead to breakthroughs a few decades later, and to continue their research without seeking immediate results and to set a good example for young people who will become the next generation of researchers.

In April 2006, students who received a high school education under the new educational guidelines that reduced the curriculum by two-thirds compared with the conventional one entered universities. Reduction in the curriculum means that the knowledge of the new students is limited; however, it is more significant that the hurdles to be surmounted are few in number in the new curriculum. In addition to receiving educational instruc- tion, the purpose of education is to build spiritual strength through training so that students can endure severe trials. Even if students cannot achieve success after years of training, their efforts surely will be useful when they reach maturity as adults.

If the starting point of education for young people is letting them be impressed with success after suffering hardships and motivating them to become spirited researchers and engineers, I would greatly appreciate it if excellent research results could be shared with readers who look through the articles in this academic journal and if readers could also be impressed by such results as well as by the authors who conducted the research and prepared the articles.

Hiroshi KANAI 